\title{
The Time for more Deliberative Citizen Participation has come
}

\author{
Mandl Stangl J* \\ Stadtbergen Leitershofen, Germany
}

*Corresponding author: Jorge Mandl Stangl, Stadtbergen Leitershofen. Germany, Email: jorge_mandl@yahoo.com

\author{
Editorial \\ Volume 4 Issue 5
}

Received Date: October 11, 2021

Published Date: October 14, 2021

DOI: $10.23880 /$ jqhe-16000243

\section{Editorial}

\section{"major crises are also trend accelerators" Borrell, Josep, "Il mondo del dopo-Covid è già qui...", en Istituto Affari Internazionali Papers , abril de 2020}

The Covid 19 pandemic has brought with it a transformative potential in the field of health and wellbeing that needs to be seriously addressed in the coming years by policy makers, practitioners, academics and citizens in particular.

It has become clear that a new system of governance is needed in which citizens can truly and actively participate and in which collective ideas and proposals can be channeled through the institutional political cycle and ultimately be reflected in concrete solutions to social problems and concerns [1]. To achieve this dynamic of political innovation, a permanent system of citizen participation in the definition, implementation and evaluation of policies based on collective rights should be established to intervene in the social determinants of health.

Citizen participation refers to social processes that allow people's concerns, interests and values to be incorporated into governmental decisions and actions - through concerted measures and/or arrangements - that are taken to address different aspects of collective life and thus ensure a more positive impact on the sustainable development of the population.

In the field of health and well-being, civil society participation has proved to be one of the greatest challenges facing health systems. Indeed, it has become a structural principle for health promotion [2]. In this context, it is important to mention successful experiences such as the Healthy Municipalities project, which emphasises certain mechanisms of participation as a means to reinforce social inclusion, with the objective of improving or restoring the sense of belonging to the community, as well as serving as a source of emancipation, allowing direct control of decisionmaking and greater control over the political system [3].

From this participatory governance has emerged a new social actor, defined as the deliberative citizen, endowed with a set of combined rights/duties, who is competent to discuss opinions, to propose, to monitor, to evaluate, to judge and to decide [4].

Unfortunately, 'good' participation too often takes place on an ad hoc basis, rather than being formally embedded in the functioning of governments and communities over time. Citizen participation has been introduced in a piecemeal fashion, without responding to a comprehensive and predictable democratic agenda; moreover, the discourse of proactive participation in health has little contact with actual practices, especially in terms of the expected empowerment of civil society in participatory activities and their influence on health decisions.

In recent decades, there has been growing interest in deliberative methods as an innovative strategy to strengthen interaction between policy makers and citizens, promote sustainable development and contribute to decision-making on quality of life and health. The deliberative approach, developed since 1980, is based on communication as a process for discussing experiences, views and ideas in a reflective and open manner, enabling citizens to co-manage the construction of the common good.

In general terms, deliberation can be said to be the capacity to influence and transform the choices and preferences previously expressed by an actor or an institution in order to improve the quality of decisions; to increase the legitimacy and accountability of the various actors; to bring 
the needs of the community closer to the responses of public services; and to make government action more effective.

This process must take place under a broad level playing field that allows everyone to live a dignified life in which material well-being is accompanied by social esteem related to contribution to the common good and collective and moral engagement in public affairs. Through this lens, the mutual satisfaction of needs becomes a sine qua non condition for solidarity and a relationship of trust between citizens and public institutions [5].

In this sense, and by way of recommendations to help advance the future debate on citizen participation in health post-COVID-19 [6], deliberative practices should:

- Prioritise health in all policies and prepare communities to share responsibility for the governance of their own sustainable development;

- Ensure sustained dialogue by focusing on strategies and systems rather than just tactics. This requires enabling a strong participatory infrastructure: i.e. coordinated laws, processes, institutions and partnerships to act cross-sectorally;

- Consider diversity, equity and inclusion when planning an engagement initiative. They should therefore be clear on ways and objectives to identify and engage key stakeholders and affected parties;

- Breaking through the ceiling of short term, often focused on the effectiveness of experimental initiatives, to include medium/long term planning strategies focused on regular and lasting effectiveness in decision making;

- Develop mechanisms that enable citizens to: identify their interests and values, contribute ideas and formulate action plans with government that result in the delivery of services to improve health/quality of life;

- Strengthening the role of government in encouraging public participation in their communities, both through formal programmes (such as funding community dialogues that bring people together to talk about their communities) or informal support (such as acting as a coordinator and connector so that people can organically interact with each other and build networks);

- Having public servants with appropriate skills and public participation tools for their communication and negotiation strategies;
- Finding and complementing - according to their field the most appropriate balance between autonomy and institutional insertion in order to rebuild a relationship of trust between citizens and public and private institutions;

- Disseminate more initiatives through robust digital platforms to share information, open up access to data, activate public oversight of policy decisions and promote the exchange of knowledge and skills;

- Ensuring transparency of the process through continuous evaluations, through multi-stakeholder advisory councils mandated to review and monitor processes and impact at all levels; including the community ownership, collective effectiveness, community capacity and increased community competence.

\section{References}

1. Delfino F (2020) The contribution of international organizations, in particular of the European Union, to the fight against global health threats: COVID-19 and its challenges and opportunities. Araucaria 22(45): 359382.

2. World Health Organization (2005) The Bangkok Charter for Health Promotion in a Globalized World, Thailand, pp: 1-6.

3. Mandl J, Málaga H (2018) Nuevas Prácticas y Significados en Politicas Públicas Saludables en los ámbitos locales de Venezuela, Rev Est de Políticas Públicas 5(1): 50-70.

4. Serapioni M, Matos AR (2014) Citizen participation and discontent in three Southern European health systems. Social Science \& Medicine 123: 226-233.

5. Oletta JF, Mandl J, Toba M (1999) Municipios Hacia La Salud. ¿Hacia dónde vamos?. In: Mandl J, Toba M, et al. (Eds.), Proyecto Municipios hacia la Salud. Experiencia Venezolana. Tomo II, MSAS/OPS/RVMHS, Caracas, Venezuela, pp: 73-83.

6. Falanga R (2020) Citizen Participation during the COVID-19 pandemic: Insights from local practices in European cities. Friedrich-Ebert-Stiftung, Lisbon, Portugal, pp: 12. 